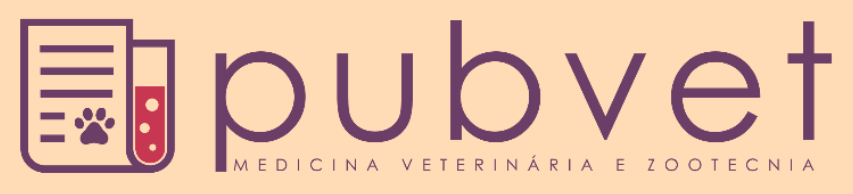

https://doi.org/10.31533/pubvet.v14n2a508.1-15

\title{
Diagnóstico de propriedades leiteiras e fatores associados à qualidade higiênico sanitária do leite
}

\author{
Eduardo Mitke Brandão Reis ${ }^{\bullet}$, Juliana Aparecida Vieira ${ }^{2} \bullet$, Marcos Aurélio Lopes $^{3^{*} \bullet}$, \\ Fabiana Alves Demeu ${ }^{4}$, Fábio Raphael Pascoti Bruhn ${ }^{\bullet}$, Fábio Henrique Vicente ${ }^{2}{ }^{\bullet}$, \\ Alessandro Botelho Pereira ${ }^{7} \bullet$, Luiz Marcos Simões Filho ${ }^{80}$ \\ ${ }^{1}$ Universidade Federal do Acre, Centro de Ciências Biológicas e da Natureza, Rio Branco, AC, Brasil. Doutorando em Ciências Veterinárias \\ pela Universidade Federal de Lavras, Lavras, MG, Brasil. \\ ${ }^{2}$ Universidade Federal de Lavras, Lavras, MG, Brasil. \\ ${ }^{3}$ Universidade Federal de Lavras, Departamento de Medicina Veterinária, Lavras, MG, Brasil. \\ ${ }^{4}$ Instituto Federal de Rondônia, Ariquemes, RO, Brasil. Doutoranda da Universidade Federal de Lavras, UFLA, Lavras, MG, Brasil. \\ ${ }^{5}$ Universidade Federal de Pelotas, Departamento de Veterinária Preventiva. Capão do Leão, RS, Brasil. \\ ${ }^{7}$ Empresa de Pesquisa Agropecuária de Minas Gerais, EPAMIG, Lavras, MG, Brasil \\ ${ }^{8}$ Universidade Federal de Lavras, Mestrando em Ciências Veterinárias, Lavras MG, Brasil. \\ *Autor para correspondência, E-mail: malopes@ufla.br
}

Resumo. Objetivou-se realizar o diagnóstico de 20 propriedades produtoras de leite, em regime de economia familiar, visando a caracterização de fatores produtivos e suas associações a aspectos relacionados à qualidade do leite. Todas as propriedades estão localizadas na micro região do Alto Rio Grande, sul de Minas Gerais. Os dados foram coletados a partir de um formulário semiestruturado, contendo 97 perguntas, no período de março a junho de 2016. Após a coleta, os dados foram cadastrados em planilhas do software Sphin $x^{\circledR}$. Os parâmetros utilizados para avaliar a qualidade do leite foram a contagem de células somáticas (CCS), contagem bacteriana total (CBT), proteína e gordura. A existência de associação entre os fatores dependentes (CCS, CBT, proteína e gordura) e independentes (as demais perguntas do formulário) foi verificada utilizando dois tipos de teste: teste $t$ de Student, quando a variável independente era qualitativa; e a correlação de Pearson ou Spearman, quando a variável independente era quantitativa. Não foram observadas diferenças $(\mathrm{p}>0,05)$ nas médias de CCS, CBT, proteína e gordura entre as categorias das variáveis independentes qualitativas. Foram observadas correlações significativas apenas entre tempo na atividade leiteira e gordura $(P=0,019 ; \mathrm{r}=-0,547) \mathrm{e}$ entre CBT e temperatura $(P=0,000 ; r=0,853)$. Alguns fatores observados durante a pesquisa, como a alta CCS e CBT, evidenciam a necessidade de melhora no manejo dentro das propriedades analisadas para que possam atender as exigências de qualidade da Instrução Normativa 62.

Palavras chave: agricultura familiar, bovinocultura leiteira, Instrução Normativa ${ }^{\circ} 62$

\section{Diagnosis of dairy properties and factors associated with sanitary hygienic of milk quality}

Abstract. The purpose of this work was to carry out the diagnosis of 20 dairy cattle properties in system of family economy, aiming the characterization of productive factors and their associations the aspects related to the quality of milk. All properties are located in the micro-region of Alto Rio Grande, southern Minas Gerais. The data were collected from a semi-structured form, containing 97 questions, in the period from March to June 2016. After collection, the data were registered in Sphinx software ${ }^{\circledR}$. The parameters used to assess the quality of milk were the somatic cell count (SCC), total bacterial count (CBT), 
protein and fat. The existence of association between the dependent factors (CCS, CBT, protein and fat) and independent (the remaining questions of the form) has been verified using two types of test: Student's t-test, when the independent variable was qualitative; and the Pearson correlation coefficient or Spearman, when the independent variable was quantitative. No statistics differences were found $(\mathrm{P}>0.05)$ in the medium of CCS, CBT, protein and fat between the categories of independent qualitative variables. Significant correlations were observed between time in the dairy activity and fat $(\mathrm{p}=0.019 ; \mathrm{r}=-0.547)$ and between CBT and temperature $(\mathrm{P}=0.000 ; \mathrm{r}=0.853)$. Some factors observed during the survey, as high CCS and CBT, demonstrate the need for improved management within the properties analyzed so that they can meet the quality requirements of Normative 62 .

Keywords: agriculture, dairy cattle, CCS, normative instruction $n^{\circ} 62$, quality of milk

\section{Diagnóstico de las propiedades lecheras y los factores asociados con la calidad higiénica sanitaria de la leche}

Resumen. El objetivo de este trabajo fue realizar el diagnóstico de 20 propiedades de ganado lechero en el sistema de economía familiar, visando caracterizar los factores productivos y sus asociaciones a aspectos relacionados con la calidad de la leche. Todas las propiedades están ubicadas en la micro región del Alto Río Grande, en el sur del estado Minas Gerais. Los datos se recopilaron de un formulario semiestructurado, que contenía 97 preguntas, en el período de marzo a junio de 2016. Después de la recopilación, los datos se registraron en Sphinx software ${ }^{\circledR}$. Los parámetros utilizados para evaluar la calidad de la leche fueron el recuento de células somáticas (SCC), el recuento bacteriano total (TCC), las proteínas y las grasas. La existencia de asociación entre los factores dependientes (CCS, TCC, proteínas y grasas) e independientes (las preguntas restantes del formulario) se verificó utilizando dos tipos de prueba: la prueba $t$ de Student, cuando la variable independiente era cualitativa; y el coeficiente de correlación de Pearson o Spearman, cuando la variable independiente era cuantitativa. No se encontraron diferencias estadísticas $(\mathrm{P}>0.05)$ en el medio de CCS, CBT, proteínas y grasas entre las categorías de variables cualitativas independientes. Se observaron correlaciones significativas entre el tiempo en la actividad láctea y la grasa $(\mathrm{P}=0.019 ; \mathrm{r}=-0.547)$ y entre la TCC y la temperatura $(\mathrm{P}=0.000 ; \mathrm{r}=0.853)$. Algunos factores observados durante la encuesta, como CCS y CBT altos, demuestran la necesidad de una mejor gestión dentro de las propiedades analizadas para que puedan cumplir con los requisitos de calidad de la Normativa 62.

Palabras clave: agricultura familiar, ganadería lechera, instrucción normativa nº 62

\section{Introdução}

O sistema agroindustrial do leite é composto por importantes segmentos para a economia brasileira, pois gera empregos, riquezas e impostos, além de ser um dos maiores do mundo (ANUALPEC, 2019; FAO, 2017). Duas características são marcantes na pecuária leiteira nacional. A primeira: a produção ocorre em todo território; a segunda: não existe um padrão de produção. É considerada uma das atividades que mais promove a distribuição de renda no país. Além disso, é fundamental para o desenvolvimento econômico da agricultura de base familiar de várias regiões brasileiras (Eurich et al., 2016).

A heterogeneidade dos sistemas de produção de leite é muito grande, assim como a sua complexidade, pois se encontram integrados por fatores biológicos, econômicos, climáticos, culturais e sociais (Lopes \& Lopes, 2001; Mattos, 1977; Payá et al., 2007). Diante disso, torna-se fundamental a caracterização das condições de produção pelos diagnósticos das necessidades de cada região auxiliando o desenvolvimento do setor lácteo (Fagnani et al., 2014).

A agricultura familiar é também de extrema importância para o país, seja pela quantidade de agricultores envolvidos, como pela garantia da produção de alimentos à população como um todo (Mochiuti et al., 2010). Segundo o Instituto Brasileiro de Geografia e Estatística (IBGE), foi constatado 
que mais da metade do leite produzido no país é proveniente de propriedades com mão-de-obra familiar, que representavam $84,4 \%$ dos estabelecimentos e eram responsáveis por $58 \%$ do total de leite produzido (IBGE, 2016; DIEESE, 2011). Diante da comprovada importância da pecuária leiteira para a agricultura familiar, bem como da crescente preocupação com métodos eficientes de produção (Eurich et al., 2013) e tendo em vista as necessidades e desejos dos consumidores e as exigências das agroindústrias por um produto de melhor qualidade, torna-se necessária uma adequação dos produtores de leite a esta nova realidade (Teixeira Júnior et al., 2015).

Com o aumento da exigência do consumidor por maior segurança alimentar, o Ministério da Agricultura, Pecuária e Abastecimento (MAPA) buscou alternativas para melhorar a qualidade do leite do país por meio da Instrução Normativa ${ }^{\circ} 51$ (IN 51), em 2002 (BRASIL, 2002). Todavia, em virtude da dificuldade do produtor de se adequar aos novos padrões, a IN 51 foi substituída pela Instrução Normativa 62 (IN 62), em 2011 (BRASIL, 2011).

Desde então, a cadeia produtiva do leite tem sofrido consideráveis modificações estruturais, aumentando a necessidade do conhecimento e caracterização das atividades nos sistemas de produção (Cerdótes et al., 2004; Ribeiro et al., 2009). Diante da importância e heterogeneidade da pecuária leiteira nacional e da crescente atenção do mercado em relação à qualidade do leite, o diagnóstico das propriedades leiteiras se torna fundamental para identificar o perfil de produção adotado na região. Os produtores precisam buscar melhoria da qualidade do produto e se adequar aos novos padrões determinados pela normativa vigente. Identificar as falhas de manejo por meio do diagnóstico das propriedades permite, então, o planejamento das atividades, através da avaliação dos resultados encontrados e a adoção de medidas que possam garantir a eficiência produtiva. Diante disso, objetivouse realizar o diagnóstico de 20 propriedades produtoras de leite, em regime de economia familiar, visando a caracterização de fatores produtivos e suas associações a aspectos relacionados à qualidade do leite.

\section{Material e métodos}

A pesquisa foi realizada em 20 propriedades, em regime de economia familiar, produtoras e fornecedoras de leite para um laticínio; todos localizados na microrregião do Alto Rio Grande, sul de Minas Gerais; no período entre março e junho de 2016. Os produtores, selecionados aleatoriamente, a partir da listagem do laticínio, independentes do volume de leite comercializado ou do sistema de produção adotados, foram entrevistados nas suas propriedades e as visitas foram acompanhadas por um técnico do laticínio; em duas propriedades o entrevistado foi um funcionário, devido à ausência do produtor.

Para as entrevistas e diagnóstico utilizou-se um formulário semiestruturado contendo 97 perguntas, adaptado de Lopes et al. (2016). Tais questões foram divididas nos temas: cadastro do produtor e da propriedade (21 questões), caracterização do rebanho (49 questões) e da produção de leite (27 questões). Nesse último tópico inclui-se o sistema de produção, manejo nutricional, escrituração zootécnica, método de identificação dos animais, criação de bezerras, controle sanitário, qualidade do leite e manejo de ordenha.

Os parâmetros utilizados para avaliar a qualidade do leite foram a CCS, CBT, proteína e gordura. Os resultados das análises de leite de cada uma das propriedades foram fornecidos pelo laticínio.

Após a coleta, os dados foram cadastrados em planilhas do software Sphinx ${ }^{\circledR}(\underline{S p h i n x}, 2011)$ e realizado o agrupamento das respostas por meio de sua categorização e frequência, conforme Bardin (2004). O software Sphinx ${ }^{\circledR}$ foi utilizado para organizar os dados, desde a concepção do formulário, passando pela inserção de dados e as diversas formas de coleta, se pergunta aberta, fechada ou de intensidade, finalizando na estruturação das respostas, análise estatística e diagramação de seu relatório. Aos dados tabulados adotouse a estatística descritiva, em relação aos valores obtidos de média, mediana, mínimo, máximo e desvio padrão das características dos produtores, do rebanho e da produção das propriedades estudadas. A existência de associação entre os fatores dependentes (CCS, CBT, proteína e gordura) e independentes (as demais perguntas do formulário) foi verificada utilizando dois tipos de teste: teste $t$ de Student. Quando a variável independente era qualitativa foi usado a correlação de Pearson ou Spearman. Considerou-se um nível de confiança mínimo de $95 \%$ em todas as análises estatísticas e estas foram realizadas utilizando o software SPSS 20.0. 


\section{Resultados e discussão}

A maioria (55\%) dos produtores entrevistado possui até o ensino fundamental incompleto; apenas um (5\%) completou o ensino médio (Tabela 1). A educação influencia de várias formas a qualidade de vida das pessoas. Ela não só afeta positivamente o nível de produtividade e renda do trabalho, como também uma população mais educada se torna capaz de participar de forma mais ativa na vida social e política do país (Ney \& Hoffmann, 2009). No meio rural de países subdesenvolvidos, Lanjouw (1999) e Reardon et al. (2001) destacam que o baixo nível de escolaridade da população restringe o crescimento das atividades, principalmente das mais produtivas e dinâmicas. (Ney \& Hoffmann, 2009) salientaram que, com um nível de escolaridade baixo, dificilmente se pode pensar em desenvolvimento rural com equidade sem uma política de expansão educacional da população mais pobre, que tende a sofrer com a escassez de dois ativos importantes na determinação de sua renda: terra para plantar e educação. Winck \& Thaler Neto (2009) verificaram que os produtores com nível educacional mais elevado (ensino médio ou superior) obtiveram resultados melhores para CBT. Este maior nível educacional pode contribuir na percepção do produtor sobre a importância da qualidade do leite e sobre a forma de aplicação das diferentes práticas de manejo de ordenha, higiene e refrigeração do leite.

Tabela 1. Perfil dos 20 produtores entrevistados e das propriedades estudadas, na microrregião do Alto Rio Grande, Minas Gerais, de março a junho de 2016

\begin{tabular}{|c|c|c|c|}
\hline \multirow{2}{*}{ Questão } & \multirow{2}{*}{ Averiguação } & \multicolumn{2}{|c|}{ Todos $(n=20)$} \\
\hline & & $\mathrm{n}$ & $\%$ \\
\hline \multirow{4}{*}{ Escolaridade do proprietário responsável } & Fundamental completo & 4 & 20,00 \\
\hline & Fundamental incompleto & 11 & 55,00 \\
\hline & Médio completo & 1 & 5,00 \\
\hline & Médio incompleto & 4 & 20,00 \\
\hline \multirow{4}{*}{ Quanto tempo iniciou na atividade pecuária (anos)? * } & Até 13 & 4 & 22,20 \\
\hline & de 14 a 27 & 6 & 33,30 \\
\hline & de 28 a 34 & 3 & 16,70 \\
\hline & 35 ou mais & 5 & 27,80 \\
\hline \multirow{4}{*}{ Área total para atividade leiteira (ha)** } & Até 19 & 8 & 50,10 \\
\hline & de 20 a 39 & 5 & 31,10 \\
\hline & de 40 a 49 & 1 & 6,30 \\
\hline & 50 ou mais & 2 & 12,50 \\
\hline \multirow{3}{*}{ A propriedade foi adquirida por: $* * *$} & Herança & 13 & 68,40 \\
\hline & Compra & 3 & 15,80 \\
\hline & Alugada & 3 & 15,80 \\
\hline \multirow{3}{*}{ Mão de obra envolvida na atividade leiteira } & Até 2 & 15 & 75,00 \\
\hline & de 3 a 4 & 4 & 20,00 \\
\hline & 5 & 1 & 5,00 \\
\hline \multirow{2}{*}{ Utiliza trabalhador temporário? } & $\overline{\mathrm{Sim}}$ & 9 & 45,00 \\
\hline & Não & 11 & 55,00 \\
\hline \multirow{2}{*}{ Participa de algum projeto? } & $\mathrm{Sim}$ & 1 & 5,00 \\
\hline & Não & 19 & 95,00 \\
\hline \multirow{2}{*}{ Possui nascente de água? } & Sim & 15 & 75,00 \\
\hline & Não & 5 & 25,00 \\
\hline \multirow{5}{*}{ Qual a origem da água que abastece a propriedade? } & Poço & 7 & 26,90 \\
\hline & Aguada & 2 & 7,70 \\
\hline & Nascente & 14 & 53,00 \\
\hline & Empresa pública & 1 & 3,80 \\
\hline & Represa & 2 & 7,70 \\
\hline \multirow{2}{*}{ Possui energia elétrica? } & $\overline{\operatorname{Sim}}$ & 20 & 100,00 \\
\hline & Não & 0 & 0,00 \\
\hline
\end{tabular}

Em casos em que a quantidade de frequências difere do total dos casos: *Dois produtores não responderam à questão; **Quatro produtores não responderam a questão; *** Um produtor não respondeu a questão.

Grande parte $(44,5 \%)$ dos produtores iniciou na pecuária leiteira há mais de 28 anos e possuem experiência de dez anos ou mais $(62,0 \%)$ na atividade produtiva da agricultura familiar. Os estabelecimentos conduzidos por produtores com menos de cinco anos de experiência representam apenas $20,0 \%$ da agricultura familiar (IBGE, 2006). A área total para atividade leiteira, em 50,10\% das propriedades, foi menor que 19 ha. Em relação à aquisição da terra, 68,40\% a adquiriram por herança e apenas $15,80 \%$ a compraram (Tabela 1$)$. Na maioria (75\%) das propriedades, existe até duas pessoas 
envolvidas na atividade leiteira. Quanto a funcionários temporários, $45 \%$ dos produtores afirmaram fazer esse tipo de contratação durante algum período do ano. Apenas um (5\%) produtor participa de algum projeto relacionado à pecuária leiteira (Tabela 1). A água utilizada em 53\% das propriedades é proveniente de nascentes e todos $(100 \%)$ possuem energia elétrica (Tabela 1).

$\mathrm{Na}$ Tabela 2 podem ser observados os valores de média, mediana, mínimo, máximo e desvio padrão das características dos produtores, do rebanho e da produção das propriedades estudadas.

Tabela 2. Estatística descritiva das características dos produtores, do rebanho e da produção das 20 propriedades estudadas na microrregião do Alto Rio Grande, Minas Gerais, de março a junho de 2016

\begin{tabular}{lccccc}
\hline Questão & Média & Mediana & Mínimo & Máximo & Desvio padrão \\
\hline Há quanto tempo iniciou na atividade pecuária (anos) & 24,44 & 26,00 & 1 & 43 & 13,36 \\
Mão de obra envolvida na atividade leiteira & 1,95 & 2,00 & 1 & 5 & 1,15 \\
Área total para atividade leiteira (ha) & 23,36 & 18,00 & 5 & 65 & 15,89 \\
Quantidade de vacas em lactação & 19,45 & 15,00 & 4 & 69 & 16,76 \\
Quantidade de vacas secas & 7,80 & 5,50 & 0 & 34 & 7,10 \\
Total de animais & 47,15 & 41,50 & 6 & 135 & 35,48 \\
Capacidade do tanque (litros) & 595,00 & 500,00 & 200 & 1.500 & 339,47 \\
Qual a distância entre a propriedade e o laticínio & 14,75 & 15,00 & 5 & 25 & 6,56 \\
Volume diário de leite produzido & 207,65 & 110,00 & 35 & 1.100 & 246,29 \\
Quantidade de leite/vaca litros) & 9,35 & 9,00 & 4 & 18 & 3,88 \\
\hline
\end{tabular}

Apenas um (5\%) produtor possuía mais que 50 vacas em lactação e, quando considerado um rebanho total, apenas três (15\%) possuíam mais de 100 animais (Tabela 3). Fagnani et al. (2014) verificaram predomínio de propriedades de pequeno porte, com média de 18,6 animais por propriedade. A quantidade de animais em lactação foi de 7,4 e a produtividade de leite diária foi de 6,0 litros por animal, o que é considerada baixa. $\mathrm{O}$ perfil de pequena produção é confirmado pela pequena quantidade de animais em lactação. Em estudo semelhante, Nero et al. (2009) observaram, em 51 propriedades (85,0\%) menos que 15 animais em lactação, oito $(13,3 \%)$ apresentaram de 16 a 30 e em apenas uma $(1,7 \%)$ foi verificado mais de 30 animais em lactação.

Em apenas uma propriedade (5\%) os animais eram da raça holandesa. Nas demais $(95 \%)$ predominavam apenas animais sem raça definida (Tabela 3). Fagnani et al. (2014) evidenciaram que animais de raça não definida e Girolanda foram os mais observados nas propriedades, com frequência de $50,0 \%$ e $16,7 \%$, respectivamente, seguidos por animais do cruzamento entre a raça Holandesa e Girolanda $(6,9 \%)$ e Girolanda e Jersey $(4,9 \%)$. A frequência da raça pura Holandesa foi observada em $4,9 \%$ e da raça pura Jersey em $2,0 \%$. Todos os outros cruzamentos somaram $14,7 \%$.

Em nenhuma das propriedades existe agrupamento das vacas lactantes. As vacas permaneciam juntas, independente de estádio de lactação ou nível de produção (Tabela 3). A fim de facilitar o trabalho operacional com vacas leiteiras em lactação, bem como aumentar a precisão no fornecimento de nutrientes para os animais em mantença ou produção, o agrupamento alimentar animal é uma prática fundamental. $\mathrm{O}$ sistema deve ser planejado para minimizar o trabalho e tirar o máximo proveito do estádio fisiológico do animal. O conceito de agrupamento dos animais é a criação de grupos que venham a ser o mais uniforme possível em tamanho, idade, produção e estádio de lactação e/ou condição reprodutiva. A vantagem geral, sob o ponto de vista nutricional, é o suprimento das exigências nutricionais dos diferentes grupos, a redução dos custos com alimentação por animal por dia e a opção para fornecer suplementos especiais (Gonçalves et al., 2009).

Em $85 \%$ é realizado o aleitamento natural dos bezerros. O fornecimento diário de ração por vaca em lactação é de acordo com a quantidade de leite produzido em $65,0 \%$ das propriedades. Quanto ao fornecimento de volumoso, $84,2 \%$ o fornecem com restrição de quantidade. Segundo Sniffen et al. (1993), a capacidade dos animais de consumir alimentos em quantidades suficientes para alcançar suas exigências de mantença e produção é um dos fatores mais importantes em sistemas de alimentação. $\mathrm{O}$ fornecimento de sal mineral foi encontrado em todas as propriedades. 
Os proprietários afirmaram, em $85,7 \%$ dos casos, identificar as vacas em lactação por meio de nome. A identificação segura dos animais é a base para todas as funções do sistema de manejo, que resultam em progressos zootécnicos, controle e economia da produção (Lopes Junior et al., 2012). Como sistema de produção, os animais são mantidos a pasto em sistema extensivo, durante todo o período do ano, em todas as propriedades (Tabela 3 ).

Tabela 3. Caracterização do rebanho e sistema de produção das 20 propriedades estudadas na microrregião do Alto Rio Grande, Minas Gerais, de março a junho de 2016

\begin{tabular}{|c|c|c|c|}
\hline \multirow{2}{*}{ Questão } & \multirow{2}{*}{ Averiguação } & \multicolumn{2}{|c|}{ Todos $(n=20)$} \\
\hline & & $\mathrm{n}$ & $\%$ \\
\hline \multirow{4}{*}{ Quantidade de vacas em lactação } & Até 19 & 13 & 65,00 \\
\hline & de 20 a 39 & 3 & 15,00 \\
\hline & de 40 a 49 & 3 & 15,00 \\
\hline & 50 ou mais & 1 & 5,00 \\
\hline \multirow{4}{*}{ Quantidade de vacas secas } & Até 3 & 3 & 15,00 \\
\hline & de 4 a 7 & 9 & 45,00 \\
\hline & de 8 a 9 & 3 & 15,00 \\
\hline & 10 ou mais & 5 & 25,00 \\
\hline \multirow{4}{*}{ Total de animais } & Até 39 & 9 & 45,00 \\
\hline & de 40 a 79 & 7 & 35,00 \\
\hline & de 80 a 99 & 1 & 5,00 \\
\hline & 100 ou mais & 3 & 15,00 \\
\hline \multirow{2}{*}{ Raça bovina predominante* } & Mestiço & 20 & 100,00 \\
\hline & Holandês & 1 & 5,00 \\
\hline \multirow{2}{*}{ Critério para agrupamento das vacas } & Não separa & & 100,00 \\
\hline & Outro & & 0,00 \\
\hline \multirow{3}{*}{ Como é oferecido o leite para os bezerros? } & Artificial c/ mamadeira & 3 & 15,00 \\
\hline & Artificial com balde & 0 & 0,00 \\
\hline & Natural & 17 & 85,00 \\
\hline \multirow{6}{*}{ Qual o consumo diário de ração por vaca em lactação? } & Não há & 1 & 5,00 \\
\hline & Até $1 \mathrm{~kg}$ & 1 & 5,00 \\
\hline & Até $3 \mathrm{~kg}$ & 2 & 10,00 \\
\hline & Mais de $3 \mathrm{~kg}$ & 2 & 5,00 \\
\hline & Pela quantidade de leite produzida & 1 & 65,00 \\
\hline & Quantidade (balde, lata, vasilhame, etc) & 13 & 10,00 \\
\hline \multirow{2}{*}{ Qual o consumo de volumoso? } & A vontade & 3 & 15,80 \\
\hline & Com restrições de quantidade & 16 & 84,20 \\
\hline \multirow{2}{*}{ Fornece sal mineral para os bovinos? } & Sim & 20 & 100,00 \\
\hline & Não & 0 & 0,00 \\
\hline \multirow{2}{*}{ Identificação das vacas* } & Brinco & 3 & 14,30 \\
\hline & Nome & 18 & $85,7,0$ \\
\hline \multirow{3}{*}{ Sistema de produção } & Pasto & 20 & 100,00 \\
\hline & Semi confinado & 0 & 0,00 \\
\hline & Confinado & 0 & 0,00 \\
\hline
\end{tabular}

*Em casos em que a quantidade de frequências difere do total dos casos: um produtor possui os dois sistemas.

Todos os produtores (100\%) produziam leite cru refrigerado e forneciam in natura para o laticínio, com tempo de armazenamento de dois dias (Tabela 4), estando em conformidade com a Instrução Normativa $\mathrm{n}^{\circ} 51$ (BRASIL, 2002), que preconiza que os tanques devem ter capacidade mínima de armazenar a produção de acordo com a estratégia de coleta e, no caso de tanque de refrigeração por expansão direta, ser dimensionado de modo tal que permita refrigerar o leite até temperatura igual ou 
inferior a $4^{\circ} \mathrm{C}$ no tempo máximo de três horas após o término da ordenha, independentemente de sua capacidade. Apenas um produtor fornecia o produto in natura e também produzia queijo tipo mussarela.

Dentre os produtores, $35 \%$ moravam $8 \mathrm{~km}$, ou mais, do local de processamento do leite, sendo o transporte do leite realizado por meio de caminhão com tanque térmico. Quando considerado o volume de leite diário produzido, foi menor que 200 litros em $65 \%$ das propriedades. Em $20 \%$ das propriedades, a média de leite foi menor que seis litros/vaca/dia (Tabela 4). Fagnani et al. (2014) evidenciaram que em 201 propriedades leiteiras, localizadas na região central do Paraná, foram, na sua maioria, pequenas extensões de terra, de agricultura familiar, caracterizadas por animais de baixa produção, pouca tecnificação e mão de obra não qualificada.

Tabela 4. Caracterização da produção de leite nas 20 propriedades estudadas na microrregião do Alto Rio Grande, Minas Gerais, de março a junho de 2016.

\begin{tabular}{|c|c|c|c|}
\hline \multirow{2}{*}{ Questão } & \multirow{2}{*}{ Resposta } & \multicolumn{2}{|c|}{ Todos $(n=20)$} \\
\hline & & $\mathrm{n}$ & $\%$ \\
\hline \multirow{3}{*}{ Tipo de leite produzido } & Tipo A & 0 & 0,00 \\
\hline & Cru refrigerado & 20 & 100,00 \\
\hline & Pasteurizado & 0 & 0,00 \\
\hline \multirow{2}{*}{ Qual o destino do leite produzido*? } & In natura & 20 & 100,00 \\
\hline & Mussarela & 1 & 5,00 \\
\hline \multirow{2}{*}{ Por quanto tempo o leite fica armazenado na propriedade? } & $1 \mathrm{dia}$ & 0 & 0,00 \\
\hline & 2 dias & 20 & 100,00 \\
\hline \multirow{3}{*}{ Armazena leite na propriedade? } & Sim & 20 & 100,00 \\
\hline & Não & 0 & 0,00 \\
\hline & 6 meses & 7 & 70,00 \\
\hline \multirow{2}{*}{ Se mecânica, frequência de troca de teteiras** } & 5 meses & 1 & 10,00 \\
\hline & 750 horas & 1 & 10,00 \\
\hline \multirow{6}{*}{$\begin{array}{l}\text { Qual a capacidade do tanque de expansão ou imersão } \\
\text { (litros)? }\end{array}$} & 90 dias & 1 & 10,00 \\
\hline & Até 599 & 8 & 65,00 \\
\hline & de 600 a 999 & 3 & 15,00 \\
\hline & de 1.000 a 1.199 & 3 & 15,00 \\
\hline & de 1.200 ou mais & 1 & 5,00 \\
\hline & Até 8 & 5 & 25,00 \\
\hline \multirow{3}{*}{ Distância entre propriedade e processador de leite $(\mathrm{km})$} & de 9 a 14 & 4 & 20,00 \\
\hline & de 15 a 17 & 4 & 20,00 \\
\hline & 18 ou mais & 7 & 35,00 \\
\hline \multirow[t]{2}{*}{ Como é realizado o transporte do leite até o laticínio? } & Caminhão isotémico & 20 & 100,00 \\
\hline & Menos de 200 & 13 & 65,00 \\
\hline \multirow[t]{2}{*}{ Volume diário de leite produzido (litros) } & de 200 a 599 & 6 & 30,00 \\
\hline & de 1000 ou mais & 1 & 5,00 \\
\hline \multirow{4}{*}{ Quantidade leite/vaca (litros) } & Menos de 6 & 4 & 20,00 \\
\hline & de 6 a 9 & 7 & 35,00 \\
\hline & de 10 a 13 & 6 & 30,00 \\
\hline & 14 ou mais & 3 & 15,00 \\
\hline
\end{tabular}

Em casos em que a quantidade de frequências difere do total dos casos: $* 1$ produtor possui os dois sistemas; $* * 10$ produtores não possuíam ordenhadeira mecânica.

Todos os proprietários (100\%) realizam a vacinação dos animais contra brucelose, raiva, febre aftosa e clostridiose (Tabela 5). Em pesquisa semelhante, Nero et al. (2009) constataram que, considerando o controle de enfermidades infectocontagiosas nos animais, todos os produtores relataram realizar vacinação contra febre aftosa, enquanto $19(31,7 \%)$ relataram vacinar contra carbúnculo sintomático e apenas sete $(11,7 \%)$ contra raiva. 
Em duas propriedades $(10 \%)$, os produtores afirmaram ter incidência de problemas de casco e em nenhuma (0\%) possuía pedilúvio (Tabela 5). O pedilúvio, que tem a finalidade de controlar os processos infecciosos podais e aumentar a resistência dos tecidos córneos, deve ser utilizado três a quatro vezes por semana (Ferreira et al., 2004).

Tabela 5. Caracterização de alguns aspectos da sanidade nas 20 propriedades estudadas na microrregião do Alto Rio Grande, Minas Gerais, de março a junho de 2016.

\begin{tabular}{|c|c|c|c|}
\hline \multirow{2}{*}{ Questões } & \multirow{2}{*}{ Respostas } & \multicolumn{2}{|c|}{ Total $(n=20)$} \\
\hline & & $\mathrm{n}$ & $\%$ \\
\hline \multirow{5}{*}{ Vacinas aplicadas regularmente } & Brucelose & 20 & 100,00 \\
\hline & Raiva & 20 & 100,00 \\
\hline & Febre aftosa & 20 & 100,00 \\
\hline & Clostridioses & 20 & 100,00 \\
\hline & (manqueira) & & \\
\hline \multirow{3}{*}{ Taxa de infestação de carrapatos em vacas } & Baixa & 13 & 65,00 \\
\hline & Média & 0 & 0,00 \\
\hline & Alta & 7 & 35,00 \\
\hline \multirow{3}{*}{$\begin{array}{l}\text { Qual o critério utilizado para controle de } \\
\text { carrapatos*? }\end{array}$} & Grau de infestação & 14 & 82,40 \\
\hline & Intervalo fixo & 3 & 17,60 \\
\hline & De acordo com o produto comprado & 0 & 0,00 \\
\hline \multirow{3}{*}{ Taxa de infestação de bernes em vacas } & Baixa & 16 & 80,00 \\
\hline & Média & 1 & 5,00 \\
\hline & Alta & 3 & 15,00 \\
\hline \multirow{3}{*}{$\begin{array}{l}\text { Taxa de infestação de mosca do chifre em } \\
\text { vacas }\end{array}$} & Baixa & 15 & 75,00 \\
\hline & Média & 1 & 5,00 \\
\hline & Alta & 4 & 20,00 \\
\hline \multirow{3}{*}{$\begin{array}{l}\text { Taxa de infestação de mosca doméstica em } \\
\text { vacas }\end{array}$} & Baixa & 20 & 100,00 \\
\hline & Média & 0 & 0,00 \\
\hline & Alta & 0 & 0,00 \\
\hline \multirow{4}{*}{ Em qual categoria é feita a vermifugação? } & Bezerras mamando & 2 & 9,50 \\
\hline & Bezerras desmamadas & 2 & 9,50 \\
\hline & Não utiliza & 1 & 4,80 \\
\hline & Toda população bovina & 15 & 76,20 \\
\hline \multirow{2}{*}{ Existe problemas de casco? } & Sim & 2 & 10,00 \\
\hline & Não & 18 & 90,00 \\
\hline \multirow{2}{*}{ Faz uso de pedilúvio? } & Sim & 0 & 0,00 \\
\hline & Não & 20 & 100,00 \\
\hline \multirow{3}{*}{ Qual o critério para secar uma vaca? } & Produção & 2 & 10,00 \\
\hline & Período antes do parto & 17 & 85,00 \\
\hline & Outros & 1 & 5,00 \\
\hline \multirow{3}{*}{$\begin{array}{l}\text { As vacas são secas quantos dias antes do } \\
\text { parto? }\end{array}$} & 60 dias & 16 & 80,00 \\
\hline & Pela baixa produção de leite & 2 & 10,00 \\
\hline & Seca sozinha & 2 & 10,00 \\
\hline \multirow{3}{*}{ Como é feita a secagem das vacas? } & Faz uso de tratamento vaca seca em todas as vacas & 10 & 50,00 \\
\hline & Faz tratamento quando há necessidade & 5 & 25,00 \\
\hline & Não faz uso de tratamento vaca seca & 5 & 25,00 \\
\hline \multirow{2}{*}{ Possui maternidade? } & Sim & 3 & 15,00 \\
\hline & Não & 17 & 85,00 \\
\hline
\end{tabular}

*Em casos em que a quantidade de frequências difere do total dos casos. 
Como critério para secagem das vacas, $85 \%$ dos produtores considera o período pós-parto; dentre eles, $80 \%$ secam as vacas 60 dias antes do parto. O tratamento, contra mastite, de todas as vacas no dia da secagem foi relatado por $50 \%$ dos produtores; enquanto que $25 \%$ fazem uso do tratamento apenas quando julgam necessários (Tabela 5). O tratamento das vacas no dia da secagem tem por finalidade a cura de infecções subclínica e a prevenção de novas infecções no período seco. Nas primeiras semanas pós-secagem a taxa de risco para novas infecções é muito alta. O ideal é tratar todas as vacas ao secar, por via intramamária com medicamento de longa ação (Lopes et al., 2013; Martins et al., 2007; Mendonça et al., 1999).

Dentre os entrevistados, $15 \%$ possuem piquete maternidade (Tabela 5). A falta de maternidade pode se tornar um problema, pois tem como finalidade principal as observações frequentes permitindo o monitoramento dos partos, caso haja necessidade de intervenção, garantindo que o bezerro nasça em um ambiente limpo e seco (Head, 1996; Santos et al., 1993).

O laticínio realiza análises de CBT, CCS, proteína, gordura e temperatura em todas as propriedades três vezes ao mês. Nenhum produtor realiza higienização do úbere e $90,0 \%$ deles realizam higienização das tetas; destes, $77,8 \%$ afirmaram realizar apenas pré-dipping como medida de higiene. Todos (100\%) utilizam cloro como produto para a realização do pré-dipping. Apenas 55,0\% dos produtores realizam o pós-dipping e, dentre eles, $90,9 \%$ utilizam o iodo para tal. Os principais produtos utilizados para higienização dos utensílios e das ordenhadeiras, após a ordenha, são detergentes alcalino, ácido e neutro; $65,0 \%$ utilizam água em temperatura ambiente (Tabela 6). A qualidade do leite in natura é influenciada por muitas variáveis, entre as quais se destacam fatores zootécnicos associados ao manejo, alimentação, potencial genético dos rebanhos e fatores relacionados à obtenção e armazenagem do leite (Kitchen, 1981). Santana et al. (2001) também relacionam a má qualidade do leite cru a fatores como índices elevados de mastite, manutenção e desinfecção inadequadas dos equipamentos, refrigeração ineficiente ou inexistente e mão de obra desqualificada, entre outros. A CBT, a ausência de resíduos de antibióticos e outros inibidores são os principais quesitos contemplados para aferir a qualidade do leite (Teixeira Júnior et al., 2015).

Tabela 6. Parâmetros associados a qualidade do leite e manejo de ordenha nas 20 propriedades estudadas na microrregião do Alto Rio Grande, Minas Gerais, de março a junho de 2016.

\begin{tabular}{|c|c|c|c|}
\hline \multirow{2}{*}{ Questão } & \multirow{2}{*}{ Resposta } & \multicolumn{2}{|c|}{ Total $(n=20)$} \\
\hline & & $\mathrm{n}$ & $\%$ \\
\hline \multirow{2}{*}{ O laticínio realiza alguma análise do leite? } & Sim & 20 & 100,00 \\
\hline & Não & 0 & 0,00 \\
\hline \multirow{5}{*}{ Quais análises são realizadas? } & Temperatura & 20 & 100,00 \\
\hline & $\mathrm{CCS}^{* *}$ & 20 & 100,00 \\
\hline & $\mathrm{CBT}^{* * / \mathrm{UFC}^{* *}}$ & 20 & 100,00 \\
\hline & Gordura & 20 & 100,00 \\
\hline & Proteína & 20 & 100,00 \\
\hline \multirow{2}{*}{ Realiza higienização do úbere? } & Sim & 0 & 0,00 \\
\hline & Não & 20 & 100,00 \\
\hline \multirow{2}{*}{ Realiza higienização das tetas? } & Sim & 18 & 90,00 \\
\hline & Não & 2 & 10,00 \\
\hline \multirow{3}{*}{$\begin{array}{l}\text { Caso sim, como é feita a } \\
\text { higienização das tetas*? }\end{array}$} & Lava com água e seca & 2 & 11,10 \\
\hline & Lava com água seca e faz pré-dipping & 2 & 11,10 \\
\hline & Apenas pré-dipping & 14 & 77,80 \\
\hline Se realiza pré-dipping, qual o produto utilizado*? & Cloro & 16 & 100,00 \\
\hline \multirow{2}{*}{ Realiza o pós-dipping } & Sim & 11 & 55,00 \\
\hline & Não & 9 & 45,00 \\
\hline \multirow{2}{*}{ Se sim, qual o produto utilizado*? } & Iodo & 10 & 90,90 \\
\hline & Dermagel & 1 & 9,10 \\
\hline \multirow{2}{*}{ Qual a temperatura da água para limpeza? } & Temperatura ambiente & 13 & 65,00 \\
\hline & Morna & 7 & 35,00 \\
\hline
\end{tabular}

*Em casos em que a quantidade de frequências difere do total dos casos; **CCS: Contagem de Células Somáticas; **CBT: Contagem Bacteriana Total; **UFC: Unidades Formadoras de Colônia. 
A maioria dos produtores entrevistados $(63,1 \%)$ apresentou a temperatura do leite em até $4^{\circ} \mathrm{C}$. A temperatura inapropriada proporciona ambiente favorável para aumento da CBT (Taffarel et al., 2013). Almeida et al. (2016) relataram altos valores de CBT e CCS das amostras armazenadas em temperatura ambiente de $25^{\circ} \mathrm{C}$ e ressaltam a importância da refrigeração para cessar o crescimento bacteriano nas amostras de leite cru, pois temperatura de $4^{\circ} \mathrm{C}$ inibe a multiplicação bacteriana e a quantidade de microorganismos permanece estável por até 48 horas. Após esse tempo há proliferação de bactérias que alteram características do leite, influenciando a qualidade da matéria-prima a ser processada pela indústria, prejudicando, consequentemente, a qualidade dos produtos lácteos nos laticínios (Andrade et al., 2014; Pinto et al., 2006; Rosa et al., 2012).

A CCS (células/ml x 1.000) ficou dentro do que determina a IN 62 em apenas 30\% dos sistemas de produção e da CBT (UFC/ml x 1.000) obteve índice ainda pior, com apenas $15 \%$ das propriedades dentro do que determina a legislação vigente (Tabela 7). Para o produtor, alta CCS e alta CBT significa menor retorno econômico, em decorrência das penalidades aplicadas pelos laticínios (Lopes et al., 2008; Lopes et al., 2012; Paixão et al., 2014; Teixeira Júnior et al., 2015) e por estarem relacionadas com redução da produção (Demeu et al., 2016) e no rendimento, em razão dos teores inferiores de caseína, gordura e lactose, que resultam em produtos de baixa qualidade e estabilidade (Müller, 2002; Nero et al., 2009; Pinto et al., 2006; Rosa et al., 2012). Na Tabela 8 podem ser observados valores de algumas medidas estatísticas descritivas das propriedades estudadas.

Tabela 7. Resultados das análises de qualidade do leite das 20 estudadas na microrregião do Alto Rio Grande, Minas Gerais, de março a junho de 2016.

\begin{tabular}{lccccc}
\hline Temperatura $\left({ }^{\circ} \mathrm{C}\right)$ & $<3,10,5 \%$ & 3 a 4, 52,60\% & 4 a $5,21,10 \%$ & 5 a $7,10,5 \%$ & $>7,5,3 \%$ \\
\hline CCS* (células/ml x 1.000) & $<400,30 \%$ & $400-1500,55 \%$ & $1500-2000,5,00$ & $2000-2500,5,00>2.500,5 \%$ \\
CBT**/UFC*** (UFC/ml x 1.000) & $<100,15 \%$ & $100-800,65 \%$ & $800-1200,10 \%$ & $1200-2000,0 \%$ & $>2.000,5 \%$ \\
Proteína (\%) & $<3,04,15 \%$ & $3,04-3,12,20 \%$ & $3,12-3,20,15 \%$ & 3,20 a $3,36,25 \%$ & $>3,36,25 \%$ \\
Gordura (\%) & $<2,7,5 \%$ & $2,7-3,3,5 \%$ & $3,3-3,6,40 \%$ & $3,6-3,9,35 \%$ & $>3,9,15 \%$ \\
\hline
\end{tabular}

*CCS: Contagem de Células Somáticas; **CBT: Contagem Bacteriana Total; ***UFC: Unidades Formadoras de Colônia.

Tabela 8. Estatística descritiva das análises de qualidade do leite das 20 propriedades estudadas na microrregião do Alto Rio Grande, Minas Gerais, de março a junho de 2016.

\begin{tabular}{lccccc}
\hline Parâmetros & Média & Mediana & Mínimo & Máximo & Desvio padrão \\
\hline Temperatura $\left({ }^{\circ} \mathrm{C}\right)$ & 4,17 & 3,80 & 2,50 & 10,3 & 1,73 \\
Gordura $(\%)$ & 3,55 & 3,54 & 2,54 & 4,13 & 0,40 \\
CCS* (células/mL x 1.000) $^{*} / \mathrm{CBC}^{* * / U F *},(\mathrm{UFC} / \mathrm{mL}$ x 1.000) & 828,95 & 609,50 & 52,00 & $3.114,00$ & 758,24 \\
Proteína (\%) & 385,35 & 165,50 & 4,00 & $2.491,00$ & 564,64 \\
\hline
\end{tabular}

*CCS: Contagem de Células Somáticas; **CBT: Contagem Bacteriana Total; ***UFC: Unidades Formadoras de Colônia.

A grande maioria $(95,0 \%)$ dos produtores entrevistados reside na propriedade e $30 \%$ contratam assistência técnica. Afirmaram procurar algum tipo de capacitação técnica, 50,0\% dos produtores. Dos produtores, 85,0\% não realizam tratamento de água. Os proprietários afirmaram não fazer escrituração zootécnica em 60,0\% dos casos (Tabela 9). Para Quirino et al. (2004)e, os benefícios em se implantar um programa de escrituração zootécnica nas propriedades rurais, dentre outros, são possuir informações zootécnicas e registros de produtividade, ter o controle do manejo na propriedade e informações referentes à sanidade do rebanho além de conhecer os dados de identificação dos animais.

Considerando a melhoria da qualidade do leite, $70,0 \%$ dos produtores afirmaram não ter metas. Em relação ao tipo de ordenha, 50,0\% possuíam ordenhadeira mecânica e, em 50\%, a ordenha era manual (Tabela 9). Para Radostits et al. (2010), o equipamento de ordenha desempenha um papel fundamental na eficiência da operação de uma propriedade leiteira.

Não foi observada diferença nas médias $(\mathrm{P}>0,05)$ de CCS, CBT, proteína e gordura entre as categorias das variáveis independentes qualitativas coletadas por meio de questionário e testadas pelo teste t de Student (Tabela 9). 
Tabela 9. Influência de fatores produtivos e de manejo sobre a qualidade do leite em 20 propriedades estudadas na microrregião do Alto Rio Grande, Minas Gerais, de março a junho de 2016.

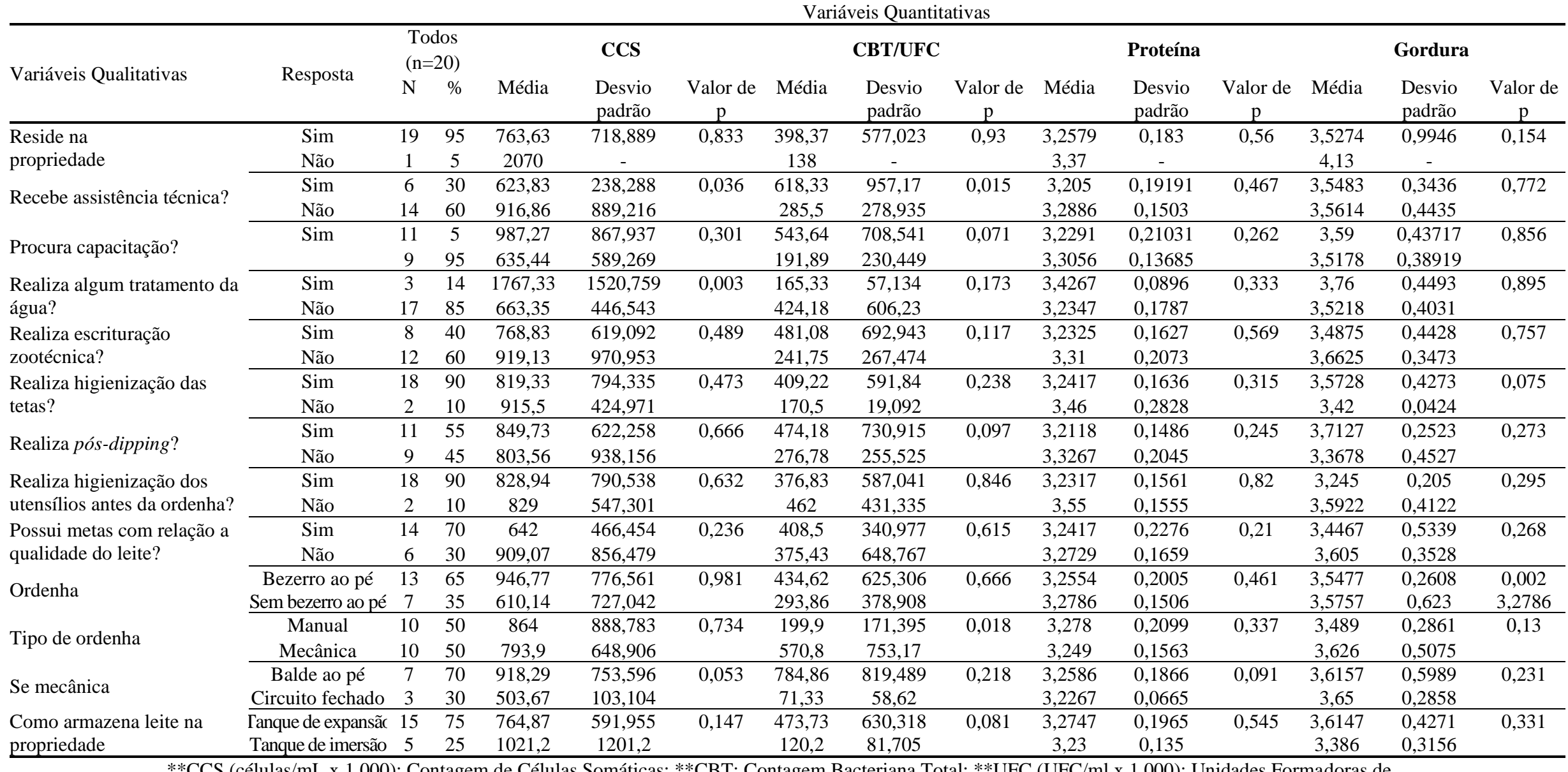

**CCS (células/mL x 1.000): Contagem de Células Somáticas; **CBT: Contagem Bacteriana Total; **UFC (UFC/ml x 1.000): Unidades Formadoras de 
Às análises de correlação, aplicadas entre as variáveis de natureza quantitativa, foram observadas correlações significativas entre tempo na atividade leiteira e gordura $(P=0,019 ; r=-0,547)$ e entre $C B T$ e temperatura $(\mathrm{P}=0,000 ; \mathrm{r}=0,853)$.Além disso, foi verificado que a capacidade do tanque apresentou correlações significativas $(\mathrm{P}>0,05)$ com a quantidade de mão de obra envolvida na atividade $(\mathrm{P}=0,00 ; \mathrm{r}=$ $0,716)$; quantidade de vacas em lactação $(\mathrm{P}=0,000 ; \mathrm{r}=0,710)$; total de animais $(\mathrm{P}=0,001 ; \mathrm{r}=0,688)$; volume de leite produzido $(\mathrm{P}=0,000 ; \mathrm{r}=0,864)$; e volume de leite vendido $(\mathrm{P}=0,000 ; \mathrm{r}=0,870)$ (Tabela 10). O crescimento da produção, acompanhado de maior quantidade de vacas em lactação, pode demandar mais mão-de-obra para realizar o manejo relacionado à produção de leite, o que explicaria a correlação significativa. Em relação ao total de animais, seu aumento pode favorecer maior produção de leite, se considerar um aumento também das vacas em lactação.

Neste estudo foram observadas correlações significativas entre o tempo na atividade leiteira e gordura $(\mathrm{P}=0,019 ; \mathrm{r}=-0,547)$ e entre CBT e temperatura $(\mathrm{P}=0,000 ; \mathrm{r}=0,853)$ (Tabela 10). A temperatura inapropriada de resfriamento torna os equipamentos de resfriamento veiculadores de bactérias no leite, proporcionando ambiente favorável para aumento da CBT (Taffarel et al., 2013). Portanto, à medida que a temperatura do tanque aumenta, e se afasta da recomendada, há aumento da CBT. A quantidade de propriedades visitadas pode ter influenciado para que não ocorresse relação significativa entre o restante das variáveis analisadas.

Tabela 10. Correlação entre os fatores dependentes e independentes avaliados e relacionados a qualidade do leite, das 20 propriedades estudadas na microrregião do Alto Rio Grande, Minas Gerais, de março a junho de 2016.

\begin{tabular}{|c|c|c|c|c|c|c|c|c|}
\hline \multirow{3}{*}{ Fatores independentes } & \multicolumn{8}{|c|}{ Fatores dependentes } \\
\hline & \multicolumn{2}{|c|}{ CCS (células/ml) } & \multicolumn{2}{|c|}{ CBT (UFC/ml) } & \multicolumn{2}{|c|}{ Proteína (\%) } & \multicolumn{2}{|c|}{ Gordura (\%) } \\
\hline & $\mathrm{R}$ & Valor de $\mathrm{p}$ & $\mathrm{R}$ & Valor de $\mathrm{p}$ & $\mathrm{r}$ & Valor de $\mathrm{p}$ & $\mathrm{R}$ & Valor de $\mathrm{p}$ \\
\hline Tempo na atividade leiteira & $-0,287$ & 0,248 & $-0,186$ & 0,459 & 0,289 & 0,245 & $-0,547$ & 0,019 \\
\hline Área total para a atividade & $-0,160^{*}$ & 0,555 & $-0,058$ & 0,832 & $-0,009$ & 0,974 & $-0,023$ & 0,932 \\
\hline Quantidade vaca em lactação & $-0,206$ & 0,383 & 0,244 & 0,299 & $-0,022$ & 0,928 & $-0,60$ & 0,802 \\
\hline Quantidade de vaca seca & $-0,292^{*}$ & 0,211 & $-0,035$ & 0,885 & $-0,160$ & 0,500 & 0,007 & 0,975 \\
\hline Total de animais & $-0,189$ & 0,424 & 0,056 & 0,814 & $-0,032$ & 0,892 & $-0,121$ & 0,611 \\
\hline $\begin{array}{l}\text { Frequência de troca de } \\
\text { teteiras }\end{array}$ & $-0,425$ & 0,169 & 0,001 & 0,997 & $-0,181$ & 0,573 & 0,017 & 0,958 \\
\hline Capacidade do tanque & $-0,113$ & 0,635 & 0,193 & 0,416 & $-0,079$ & 0,739 & 0,267 & 0,255 \\
\hline Volume de leite produzido & $-0,177$ & 0,455 & $-0,030$ & 0,899 & 0,012 & 0,960 & 0,090 & 0,707 \\
\hline Volume de leite vendido & $-0,172$ & 0,470 & $-0,022$ & 0,928 & 0,012 & 0,959 & 0,078 & 0,745 \\
\hline Temperatura & 0,168 & 0,506 & 0,853 & 0,000 & $-0,268$ & 0,282 & 0,217 & 0,387 \\
\hline
\end{tabular}

r: coeficiente de correlação de Pearson; * coeficiente de correlação de Spearman, pois foi verificada ausência de distribuição normal dos dados pelo teste de Shapiro-wilk.

\section{Conclusões}

O diagnóstico das propriedades produtoras de leite permitiu correlacionar os aspectos relacionados ao manejo adotado dentro das propriedades leiteiras com à qualidade do leite produzido, o que pode ajudar os produtores a identificarem os pontos mais críticos dentro do manejo adotado.

Alguns fatores produtivos associados à qualidade do leite, encontrados nas propriedades pesquisadas, evidenciam a necessidade de melhora no manejo, para que possam ser atendidas as exigências da Instrução Normativa $\mathrm{n}^{\circ} 62$. Dentre os fatores encontrados estão a baixa porcentagem de gordura e proteína, alta CCS (células/ml) e CBT (UFC/ml).

Foram observadas correlações significativas apenas entre tempo na atividade leiteira e gordura e entre CBT e temperatura quando os fatores produtivos e a qualidade do leite foram correlacionados. Não foi observada diferença nas médias de CCS, CBT, proteína e gordura entre as categorias das variáveis independentes qualitativas.

\section{Agradecimentos}

Os autores agradecem ao CNPq, pela concessão da bolsa de produtividade em pesquisa do terceiro autor. 


\section{Referências bibliográficas}

Almeida, T. V., Neves, R. B. S., Arnhold, E., Rezende, C. S. M., Oliveira, A. N. \& Nicolau, E. S. (2016). Efeito da temperatura e do tempo de armazenamento de amostras de leite cru nos resultados das análises eletrônicas. Arquivo Brasileiro de Medicina Veterinaria e Zootecnia, 68(5):1316-1324.

Andrade, K. D., Rangel, A. H. N., Araújo, V. M., Medeiros, H. R., Bezerra, K. C., Bezerril, R. F. \& Lima Júnior, D. M. (2014). Qualidade do leite bovino nas diferentes estações do ano no estado do Rio Grande do Norte. Revista Brasileira de Ciência Veterinária, 21(3):213-216.

ANUALPEC. (2019). Anuário da Pecuária Brasileira (20th ed. Vol. 1). São Paulo, São Paulo, Brasil: Instituto FNP.

Bardin, L. (2004). Análise de conteúdo. São Paulo, Brasil.

BRASIL - Ministério da Agricultura, Pecuária e Abastecimento. Instrução Normativa $\mathrm{n}^{\circ}$ 51, de 18 de setembro, 2002. Diário Oficial da República Federativa do Brasil. Brasília, DF, 18 set. 2002. Disponível em: http://www.camara.gov.br/sileg/integras/141673.pdf> Acesso em: 22 dez. 2016.

BRASIL. Ministério da Agricultura, Pecuária e Abastecimento. Instrução normativa n ${ }^{\circ}$ 62, de 29 de dezembro de 2011. Regulamento Técnico de Produção, Identidade e Qualidade do Leite tipo A, de Leite Cru Refrigerado, de Leite Pasteurizado e o Regulamento Técnico da Coleta de Leite Cru Refrigerado e seu Transporte a Granel. Diário Oficial da República Federativa do Brasil, Brasília, 2011. Disponível em: http://www.apcbrh.com.br/files/IN62.pdf> Acesso em: 14 de nov.2016.

Cerdótes, L., Restle, J., Alves Filho, D. C., Nörnberg, M. F. B. L., Nörnberg, J. L., Heck, I. \& Silveira, M. F. (2004). Produção e composição do leite de vacas de quatro grupos genéticos submetidas a dois manejos alimentares no període de lactação. Revista Brasileira de Zootecnia, 33(3):610-622.

Demeu, F. A., Lopes, M. A., Costa, G. M., Rocha, C. M. B. M. \& Santos, G. (2016). Efeito da produtividade diária de leite no impacto econômico da mastite em rebanhos bovinos. Boletim de Indústria Animal, 73(1):53-61.

DIEESE - Departamento Intersindical de Estatística e Estudos Socioeconômicos. Estatísticas do meio rural. (2010-2011). 4ª ed. São Paulo, DIEESE/NEAD/ MDA. 2011. 292p.

Eurich, J., Weirich Neto, P. H. \& Rocha, C. H. (2013). Índices emergéticos de sustentabilidade da produção leiteira em uma propriedade de base familiar em Palmeira, Paraná, Brasil. Revista Ceres, 60(3):332-338.

Eurich, J., Weirich Neto, P. H. \& Rocha, C. H. (2016). Pecuária leiteira em uma colônia de agricultores familiares no município de Palmeira, Paraná. Revista Ceres, 63(4):454-460.

Fagnani, R., Battaglini, A. P. P., Beloti, V., Schuck, J., Seixas, F. N. \& Carraro, P. E. (2014). Parâmetros físico-químicos e microbiológicos do leite em função da sazonalidade. Revista do Instituto de Laticínios Cândido Tostes, 69(3):173-180.

FAO. (2017). Statistical Yearbook (Vol. 1). Rome, Italy: Food and Agriculture Organization of the United Nations.

Ferreira, P. M., Leite, R. C., Carvalho, A. U., Facury Filho, E. J., Souza, R. C. \& Ferreira, M. G. (2004). Custo e resultados do tratamento de seqüelas de laminite bovina: relato de 112 casos em vacas em lactação no sistema free-stall. Arquivo Brasileiro de Medicina Veterinária e Zootecnia, 56(5):589594.

Gonçalves, L. C., Borges, I. \& Ferreira, P. D. S. (2009). Alimentação de gado de leite (Vol. 1). Belo Horizonte, Minas Gerais: EPMVZ.

Head, H. H. (1996). Manejo de animais em sistema de estabulação livre visando maximizar conforto e produção. Paper presented at the Congresso Brasileiro de Gado Leiteiro - Conceitos Modernos de Exploração Leiteira, Piracicaba.

IBGE - Instituto Brasileiro de Geografia e Estatística. Censo Agropecuário do IBGE. Disponível em: <http://www.ibge.gov.br>. Acesso em 01 abr. 2016.

Kitchen, B. J. (1981). Bovine mastitis: milk compositional changes and related diagnostic tests. Journal of Dairy Research, 48(1):167-188. 
Lanjouw, P. (1999). The rural non-farm sector: a note on policy options. Paper presented at the NonFarm Workshop Background paper, The World Bank.

Lopes Junior, J. F., Ramos, C. E. C. O., Santos, G. T., Grande, P. A., Damasceno, J. C. \& Massuda, E. M. (2012). Análise das práticas de produtores em sistemas de produção leiteiros e seus resultados na produção e qualidade do leite. Semina: Ciências Agrárias, 33(3):1199-1208. doi: http://dix.doi.org/10.5433/1679-0359.2012v33n3p1199.

Lopes, L. O., Lacerda, M. S. \& Ronda, J. B. (2013). Uso de antibióticos na cura e controle de mastite clínica e subclínica causada por principais microorganismos contagiosos em bovinos leiteiros: revisão de literatura. Revista Cientifica Eletrônica de Medicina Veterinária, 21(1):1-15.

Lopes, M., Cardoso, M., Demeu, F. \& Dias, A. (2008). Composição de rebanhos bovinos leiteiros: levantamento, estimativa do dimensionamento e da evolução. Boletim da Indústria Animal, 65163 167.

Lopes, M. A., Demeu, F. A., Rocha, C. M. B. M., Costa, G. M., Franco Neto, A. \& Santos, G. (2012). Avaliação do impacto econômico da mastite em rebanhos bovinos leiteiros. Arquivos do Instituto Biológico, 79(4):477-483.

Lopes, M. A. \& Lopes, F. M. (2001). Custo de produção da pecuária e análise de rentabilidade da pecuária leiteira. Paper presented at the Simpósio goiano sobre manejo e nutrição de bovinos, Goiânia, Goiás, Brasil.

Lopes, M. A., Reis, E. M. B. \& Ferrazza, R. (2016). Formulário de diagnóstico da propriedade leiteira. Lavras, Minas Gerais, Brasil. . Lavras: Universidade Federal de Lavras.

Martins, C. R., Vieria, E. C., Gazim, Z. C. \& Massambani, C. (2007). Tratamento de mastite subclínica por meio de suplementação mineral homeopática da dieta de vacas leiteiras em lactação-estudo de caso. Cultura Homeopática, 1916-19.

Mattos, W. R. S. (1977). Sistemas de estabulação livre para bovinos. Simpósio sobre pecuária leiteira, 1123-139.

Mendonça, C. L., Fioravant, M. C. S. \& Silva, J. A. B. A. (1999). Etiologia da mastite bovina. Veterinária Notícias, 5(1):107-118.

Mochiuti, J. C., Pinto, L. d. B., Oliveira, S. C. \& Santos, G. D. d. (2010). Análise do perfil dos produtores rurais de Pracinha-SP e a representatividade da pecuária na composição da renda. Revista OMNIA Exatas, 340-52.

Müller, E. E. (2002). Qualidade do leite, células somáticas e prevenção da mastite. Paper presented at the Simpósio sobre Sustentabilidade da Pecuária Leiteira na Região Sul do Brasil, Toledo, Paraná.

Nero, L. A., Viçosa, G. N. \& Pereira, F. E. V. (2009). Qualidade microbiológica do leite determinada por características de produção. Food Science and Technology, 29(2):386-390.

Ney, M. G. \& Hoffmann, R. (2009). Educação, concentração fundiária e desigualdade de rendimentos no meio rural brasileiro. Revista de Economia e Sociologia Rural, 47(1):147-181.

Paixão, M. G., Lopes, M. A., Pinto, S. M. \& Abreu, L. R. (2014). Impacto econômico da implantação das boas práticas agropecuárias relacionadas com a qualidade do leite. Revista Ceres, 61(5):612-621.

Payá, S. B., Simões, A. C., Ferraz Filho, P. B., Silva, L. O. C. \& Souza, J. C. (2007). Causas de variações não genéticas e interações estação x região em pesos de animais de rebanhos nelore mocho em áreas inclusas na região pecuária de leiteiras. Archives of Veterinary Science, 12(2).

Pinto, C. L. O., Martins, M. L. \& Vanetti, M. C. D. (2006). Qualidade microbiológica de leite cru refrigerado e isolamento de bactérias psicrotróficas proteolíticas1. Ciência e Tecnologia de Alimentos, 26(3):645-651.

Quirino, C. R., Costa, R. L. D., Silva, R. M. C., Siqueira, J. G., Afonso, V. A. C. \& Burcher, C. H. (2004). Implementação da escrituração zootécnica e registros de produção e reprodução em propriedades de criação de ovinos na região Norte Fluminense. Paper presented at the Congresso Brasileiro de Extensão Universitária, Belo Horizonte.

Radostits, O. M., Gay, C. C., Blood, D. C., Hinchcliff, K. W. \& McKenzie, R. A. (2010). Clínica Veterinária: um tratado de doenças dos bovinos, ovinos, suínos, caprinos e eqüinos (Vol. 1). Rio de Janeiro: Guanabara Koogan. 
Reardon, T., Berdegué, J. \& Escobar, G. (2001). Rural nonfarm employment and incomes in Latin America: overview and policy implications. World development, 29(3):395-409.

Ribeiro, A. B., Tinoco, A. F. F., Ferreira, G., Guilhermino, M. M. \& Rangel, A. H. N. (2009). Produção e composição do leite de vacas Gir e Guzerá nas diferentes ordens de parto. Revista Caatinga, 22(3):46-51.

Rosa, D. C., Trentin, J. M., Pessoa, G. A., Silva, C. A. M. \& Rubin, M. I. B. (2012). Qualidade do leite em amostras individuais e de tanque de vacas leiteiras. Arquivos do Instituto Biológico, 79(4):485493. doi: https://dx.doi.org/10.1590/S1808-16572012000400004.

Santana, E. H. W., Beloti, V., Barros, M. d. A. F., Moraes, L. B., Gusmão, V. V. \& Pereira, M. S. (2001). Contaminação do leite em diferentes pontos do processo de produção: I. Microrganismos aeróbios mesófilos e psicrotróficos. Semina: Ciências Agrárias, 22(2):145-154.

Santos, G. T., Branco, A. F., Prado, I. N., Moraes, G. V. \& Zeoula, L. M. (1993). Manejo geral do rebanho leiteiro. Revista Gado Holandês, 6028-37.

Sniffen, C. J., Beverly, R. W., Mooney, C. S., Roe, M. B., Skidmore, A. L. \& Black, J. R. (1993). Nutrient requirements versus supply in the dairy cow: strategies to account for variability. Journal of Dairy Science, 76(10):3160-3178.

Sphinx Brasil. (2011) Manual de uso do software - Sphinx rápido. ed. 2, p. 47.

Taffarel, L. E., Costa, P. B., Oliveira, N. T. E., Braga, G. C. \& Zonin, W. J. (2013). Contagem bacteriana total do leite em diferentes sistemas de ordenha e de resfriamento. Arquivos do Instituto Biológico, 80(1):7-11.

Teixeira Júnior, F. E. P., Lopes, M. A. \& Ruas, J. R. M. (2015). Efeito do pagamento por qualidade do leite na rentabilidade da atividade leiteira. Revista do Instituto de Laticínios Cândido Tostes, 70(1):24-34.

Winck, C. A. \& Thaler Neto, A. (2009). Diagnóstico da adequação de propriedades leiteiras em Santa Catarina às normas brasileiras de qualidade do leite. Revista de Ciências Agroveterinárias, 8(2):164172.

Recebido: 17 de setembro, 2019.

Aprovado: 15 de novembro, 2019.

Publicado: 13 de março, 2020.

Licenciamento: Este artigo é publicado na modalidade Acesso Aberto sob a licença Creative Commons Atribuição 4.0 (CC-BY 4.0), a qual permite uso irrestrito, distribuição, reprodução em qualquer meio, desde que o autor e a fonte sejam devidamente creditados. 